\title{
An Electrosensory Area in the Telencephalon of the Little Skate, Raja erinacea
}

\author{
DAVID BODZNICK and R. GLENN NORTHCUTT ${ }^{1}$
}

Department of Biology, Wesleyan University, Middletown, CT 06457 and'Division of Biological Sciences, University of Michigan, Ann Arbor, MI (U.S.A.)

(Accepted September 6th, 1983)

Key words: elasmobranchs - electroreception - telencephalon - pallium - diencephalon - vision

\begin{abstract}
On the basis of evoked potential and multiple unit responses we identified a pallial electrosensory area that extends throughout the central one-third of the skate telencephalon. This electrosensory area coincides in its mediolateral and rostrocaudal extent with an area of visual responsiveness. Throughout the area peak visual activity is $250-500 \mu \mathrm{m}$ superficial to the maximum electrosensory responses. However, both electrosensory and visual areas appear to be located within the same pallial cell group. The depth and proximity of this pallial area to the lateral ventricle and medial forebrain bundle suggest that it is a subdivision of the medial pallium. Injection of HRP into the area from a glass microelectrode following recordings revealed retrogradely labeled cells in 3 separate diencephalic nuclei, the largest of which, the lateral posterior nucleus, also is responsive to electrosensory stimuli.
\end{abstract}

\section{INTRODUCTION}

Lateral line receptors of skates, like those of other cartilaginous fishes, include electroreceptive ampullae of Lorenzini that are located on the head and pectoral fins and are innervated by fibers of the anterior lateral line nerve10,19. These electroreceptive fibers constitute the dorsal root of the anterior lateral line nerve and terminate within the dorsal octavolateralis nucleus of the medulla2-4,16. Efferents of the dorsal octavolateralis nucleus form ipsilateral and contralateral lemnisci as well as commissural pathways. The ascending lemniscal pathways terminate in the nucleus of the lateral line lemniscus, the lateral nucleus of the lateral mesencephalic complex, and in the central zone of the optic tectum ${ }^{5}$. Electrosensory responses have also recently been recorded from the diencephalon ${ }^{25}$. Although considerable information exists regarding the pathways and neural centers mediating electroreception at brainstem levels, little information exists concerning this sensory modality in the telencephalon, beyond the fact that electroreceptive information does reach the telencephalon 7,8,22.

Using averaged evoked potential and multiple unit recordings we have identified an electrosensory area in the pallium of the skate telencephalon. The rostrocaudal and mediolateral extent of this area coincides with an area of visual evoked activity.

\section{MATERIALS AND METHODS}

\section{Electrophysiology}

Electrophysiological recordings were made from 40 adult Raja erinacea $(350-500 \mathrm{~g})$. After anesthetizing a skate by immersing it in $0.01 \%$ tricaine methanesulfonate we surgically exposed the dorsal surface of the brain. The animal was then paralyzed by intravenous injections of tubocurarine chloride $(1-5 \mathrm{mg} / \mathrm{kg})$ and positioned in the center of a large tank of refrigerated sea water $\left(10-14^{\circ} \mathrm{C}\right.$ and resistivity about $25 \Omega \cdot \mathrm{cm}$ ). A plexiglass clamp held the head ridigly in place and a continuous flow of sea water from a tube placed in one spiracle ventilated the animal.

We recorded evoked potential and multiple unit responses from the forebrain using glass microelectrodes (5-10 $\mu \mathrm{m}$ tip diameter) filled with $2 \mathrm{M} \mathrm{NaCl}$ saturated with Fast green. The signals were first amplified using a conventional extracellular preamplifier with bandpass filter settings of $0.3 \mathrm{~Hz}-3.0 \mathrm{kHz}$

Correspondence: D. Bodznick, Department of Biology, Wesleyan University, Middletown, CT 06457, U.S.A. 
and then displayed on an oscilloscope. The signal-tonoise ratio of most evoked responses was improved by signal averaging of $4-8$ responses. Iontophoretic injection of Fast green from the electrode tip marked recording sites.

As natural stimuli for the electrosense, uniform electric fields were produced in the water of the tank as DC steps from zero. The fields were delivered from a stimulator and constant current isolation unit via sets of seawater-agar bridge electrodes. The electrodes were positioned along the sides and ends of the experimental tank so that the electric fields could be oriented either parallel or transverse to the longitudinal body axis of the fish. The resultant electric fields were approximately uniform in the center of the tank where the fish was held, and were typically $10-100 \mu \mathrm{V} / \mathrm{cm}$ (about $0.4-4 \mu \mathrm{A} / \mathrm{cm}^{2}$ ) in amplitude. The duration of individual stimulus pulses was
$50-400 \mathrm{~ms}$ and iterative rates of $0.05-2.0 \%$ were used. We monitored the electric field stimuli with a pair of seawater-agar bridge electrodes positioned $10 \mathrm{~cm}$ apart near the center of the tank. Visual stimuli were diffuse light flashes.

Telencephalic electrosensory and visual areas were most easily located by direct electrical stimulation of brainstem electrosensory nuclei and the optic nerve. A concentric bipolar electrode was used to give 8-15 V shocks of $0.25-1.0 \mathrm{~ms}$ duration. To stimulate visual pathways bipolar stimulating electrodes were placed in one or both optic nerves. Electrosensory pathways were stimulated by placing the electrodes in the medullary dorsal octavolateral nucleus or in the lateral nucleus of the lateral mesencephalic complex ${ }^{5}$. Both of these electrosensory nuclei are apparent from the surface of the brain.
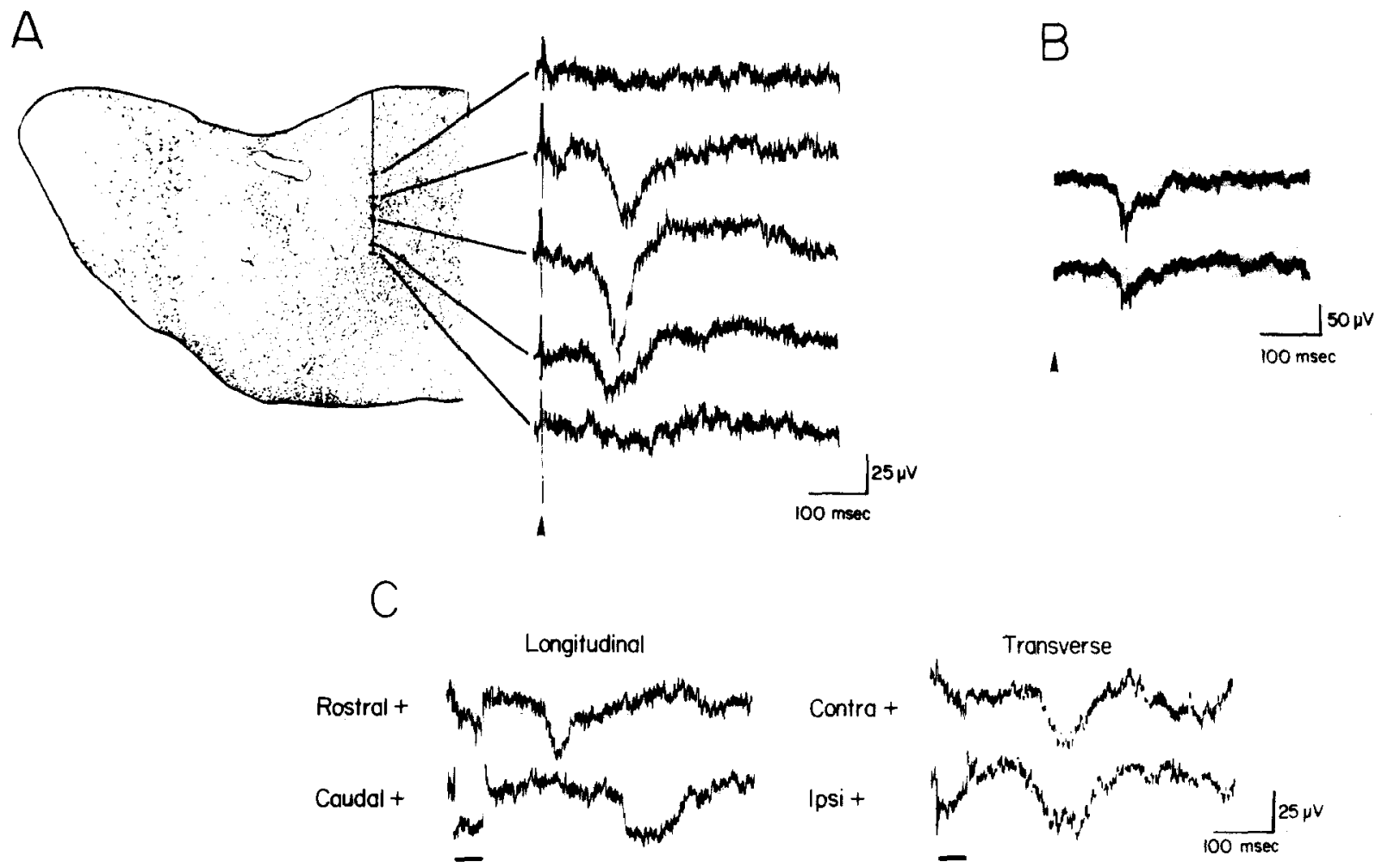

Fig. 1. Evoked responses recorded from the skate telencephalon following direct electrical stimulation (arrowheads) of the medullary electrosensory nucleus (dorsal nucleus) (A, B) or uniform E field stimuli in the water around the fish (C). A: electrosensory responses are associated with a pallial area that has been identified as the medial pallium in skates ${ }^{20}$. Each trace is the average of 4 responses. The depth of maximal activity was marked by iontophoresis of Fast green from the recording electrode. B: single unaveraged responses to DON shock at the depth of maximum activity in A show the presence of unit impulses at the peak of the evoked potential response. $\mathrm{C}$ : responses at the same location as in $\mathrm{B}$ to uniform $\mathrm{E}$ field stimuli in the water around the fish illustrate the dependence of the response on orientation and polarity of the E field. The stimulus intensity was $50 \mu \mathrm{V} / \mathrm{cm}\left(2 \mu \mathrm{A} / \mathrm{cm}^{2}\right)$ and each trace is the average of 4 trials. Positive voltages are upwards. 


\section{Anatomy}

In 3 animals we made telencephalic recordings using a glass microelectrode (3-8 $\mu \mathrm{m}$ tip diameter) filled with $20 \%$ horseradish peroxidase (Sigma VI) in pH 7.4 phosphate buffer. After recordings, about 40-100 $\mathrm{nl}$ of HRP was pressure injected from the electrode into the responsive area. The animals were then revived and maintained at $12-14^{\circ} \mathrm{C}$. After 2 weeks survival the animals were perfused with $4 \%$ gluteraldehyde-1\% paraformaldehyde in $0.1 \mathrm{M}$ phosphate buffer (pH 7.4). Thirty-five $\mu \mathrm{m}$ transverse sections of the brain were cut on a sled microtome with a freezing stage and then reacted using tetramethyl benzidine following the method of Mesulam ${ }^{18}$. Most sections were counterstained with $1 \%$ neutral red. However, occasional series were air-dried and transferred directly to xylene, without counterstaining or dehydration through graded alcohols, in order to check for potential reduction of reaction product.

\section{RESULTS}

\section{Electrosensory area in the telencephalon}

A telencephalic area responsive to electrosensory stimuli is located within a deep zone of the pallium. Weak electric fields in the water around the fish, or direct electrical stimulation of electrosensory nuclei in the brainstem elicit large evoked-potential and multiple-unit responses from this area.

Electrical stimulation of either the medullary dorsal nucleus or the lateral nucleus of the lateral mesencephalic complex results in a large negative evoked potential at depths that correspond closely to the medial pallium (Fig. 1A) as identified by Northcutt 20 . Multiple unit impulses are also evoked from this area of the telencephalon and are superimposed on the peaks of the evoked wave (Fig. 1B). The large evoked-potential response, which is apparent in single trials without signal averaging, actually appears

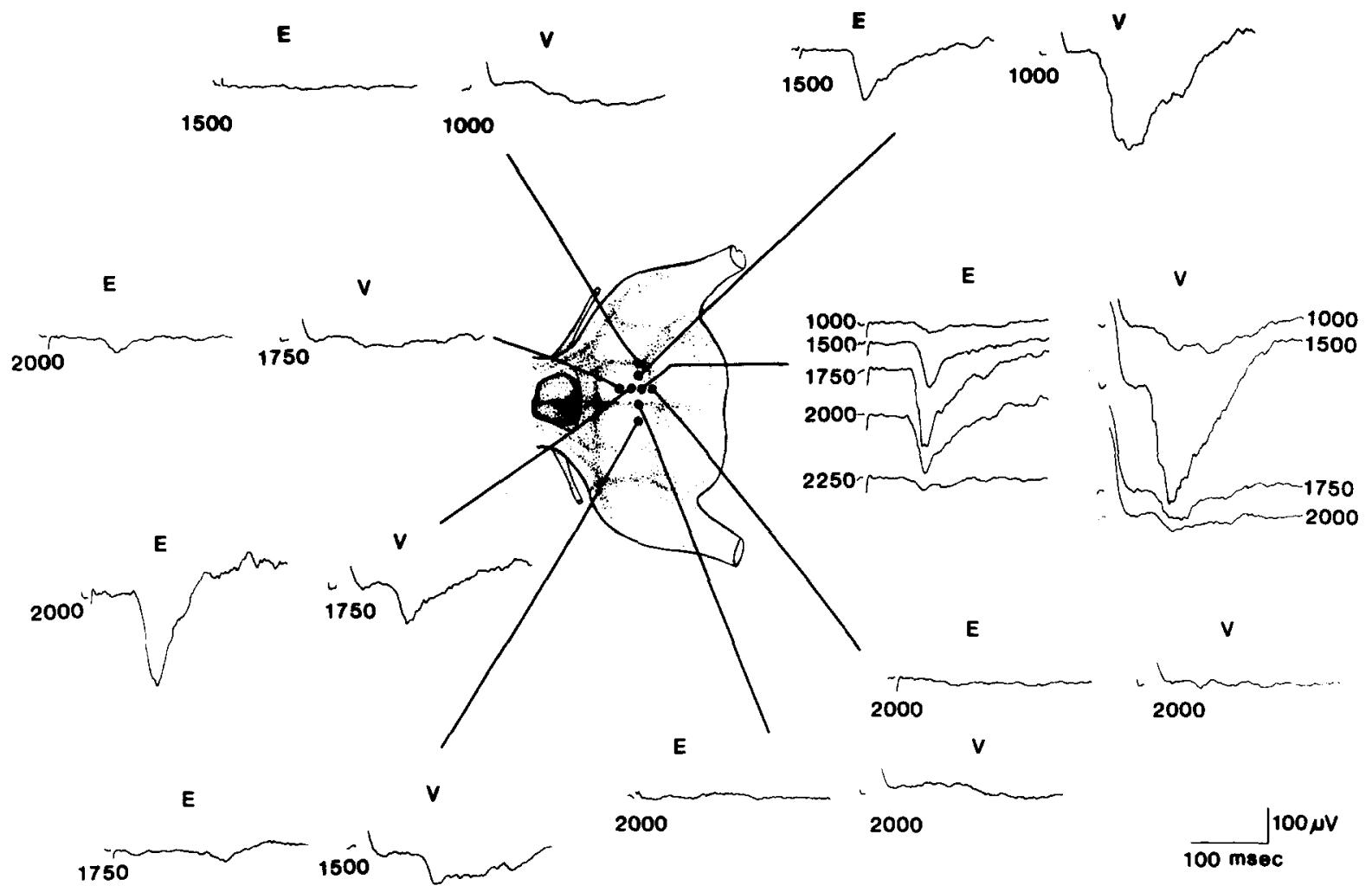

Fig. 2. Averaged evoked potential responses in the telencephalon in response to direct electrical stimulation of the dorsal nucleus (E) or optic nerve (V) on the left side of the animal. The recording location is shown on a drawing of the dorsal view of the telencephalon and the number with each record is the recording depth in $\mu \mathrm{m}$. For each track the maximum response to each stimulus is shown. Note that maximum responses to the optic nerve stimulation (V) occur at depths that are $250-500 \mu \mathrm{m}$ superficial to the maximum response with dorsal nucleus shock (E). While responses are absent on the midline, small, long-latency responses to both dorsal nucleus and optic nerve shock were found in the hemisphere contralateral to the stimulus. Positive voltages are upwards. 
to be composed of two separate negative peaks in most of our records. The response is largest in the telencephalic hemisphere ipsilateral to the dorsal nucleus that is stimulated and contralateral to the stimulated mesencephalic nucleus. However, a smaller, longer latency response can also be recorded from similar regions in the opposite telencephalic hemisphere (Fig. 2). The onset latency of the evoked response is about $70 \mathrm{~ms}$ after stimulation of the ipsilateral dorsal nucleus and $120 \mathrm{~ms}$ after contralateral dorsal nucleus stimulation.

The amplitude and latency of responses evoked by natural stimulation with weak electric fields depended on the field's intensity, orientation and polarity (Fig. 1C). The best orientation and polarity appeared to vary with recording site but we did not study this property in detail. Latencies of responses to electric fields were, as expected, longer than for responses to dorsal nucleus shock. The shortest latency observed with electric field stimuli of moderate intensity $\left(50 \mu \mathrm{V} / \mathrm{cm}\right.$; current density $\left.20 \mu \mathrm{A} / \mathrm{cm}^{2}\right)$ is about $130 \mathrm{~ms}$. With electric field stimuli of long duration (400 ms), separate responses to field onset and offset could be discerned. Telencephalic responses to weak electric fields show some habituation at stimulation rates greater than $0.05 / \mathrm{s}$ and are completely abolished at $0.8 / \mathrm{s}$.

The pallial area responsive to electrosensory stimuli extends throughout the central one-third of the telencephalon (Fig. 2). Using direct electrical stimulation of the optic nerve or diffuse light flashes, we found visual evoked responses in the same pallial area which have a nearly identical mediolateral and rostrocaudal distribution. The electrosensory area extends only slightly more caudal than the area of visual responses. However, throughout the area in which both visual and electrosensory responses are found the peak visual activity is $250-500 \mu \mathrm{m}$ superficial to the largest electrosensory responses (Fig. 2). The peak visual activity is still within the same pallial area as the electrosensory responses. At depths intermediate between the peaks of visual and electrosensory activity smaller evoked-potential and multiple-unit responses are elicited with stimuli in each modality. These results indicate that vision and electroreception have separate but overlapping laminar terminations within the pallium. Single unit recordings will be required to determine if cells in the overlapping regions are multimodal.
Like the visual responses recorded from a division of the dorsal pallium (central nucleus) in the nurse shark $^{9}$, the visual responses in the little skate are largest and have the shortest latency in the telencephalic hemisphere ipsilateral to the side stimulated. However, in contrast to these earlier studies of telencephalic visual responses, we have also recorded responses from the contralateral hemisphere which are smaller and longer in latency. Like the electrosensory evoked potentials the visual evoked wave usually consists of two overlapping negative peaks. The onset of the earliest peak is $60-90 \mathrm{~ms}$ after electrical shock to the ipsilateral optic nerve and 90-140 ms after contralateral nerve shock. An evoked potential response with the same depth profile and an identical waveform is elicited by electrical stimulation of the contralateral optic tectum. This suggests that the visual inputs to the medial pallium of skates may come, at least in part, via a retino-tecto-thalamo-telencephalic pathway.

\section{Electrosensory areas in the diencephalon}

In order to determine the diencephalic relay nuclei projecting to the electrosensory pallium, the telencephalic electrosensory area was first located by recording evoked responses using an HRP-filled glass micropipette. HRP was then pressure-injected into this area from the recording electrode. Three separate diencephalic cell groups (Fig. 3) contained cell bodies that retrogradely labeled following these injections. The single largest, labeled diencephalic nucleus, lateral posterior thalamic nucleus, is found throughout the rostrocaudal extent of the thalamus, and most of the cell bodies labeled in this nucleus are contralateral to the injection site. A caudal midline nucleus (posterior tuberal nucleus) and a rostral thalamic nucleus (anterior thalamic nucleus) were also characterized by a few retrogradely labeled cell bodies.

Recordings of evoked potential and unit responses to weak electric field stimuli revealed that electroreceptive activity was associated with one of these nuclei, the lateral posterior nucleus (Fig. 4). As in other known electrosensory areas of the brain, responses recorded from the lateral posterior nucleus to electric field stimuli depended on the orientation and polarity of the stimulus field. Evoked potential responses to fields parallel with the longitudinal axis of the fish, 

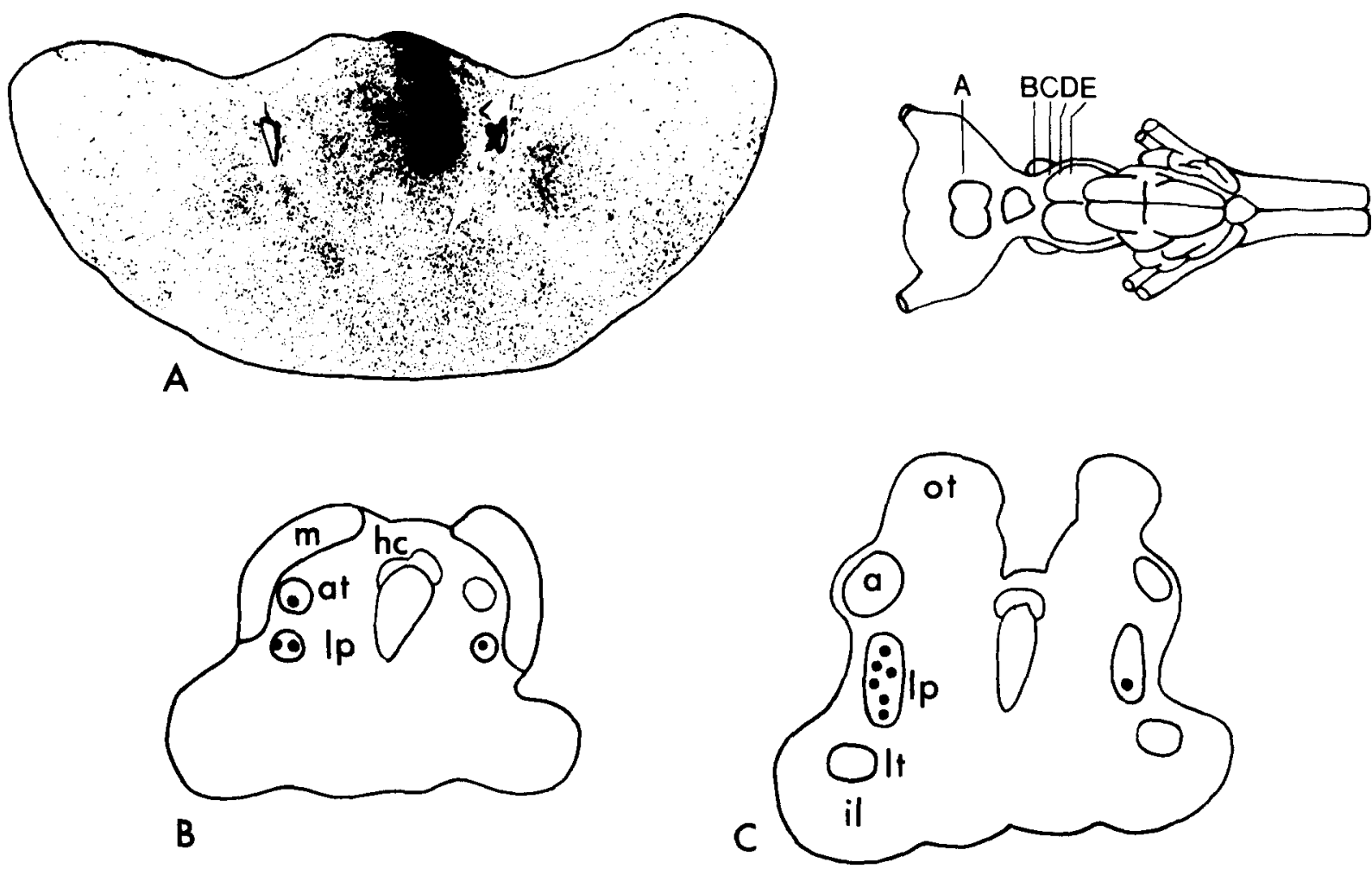

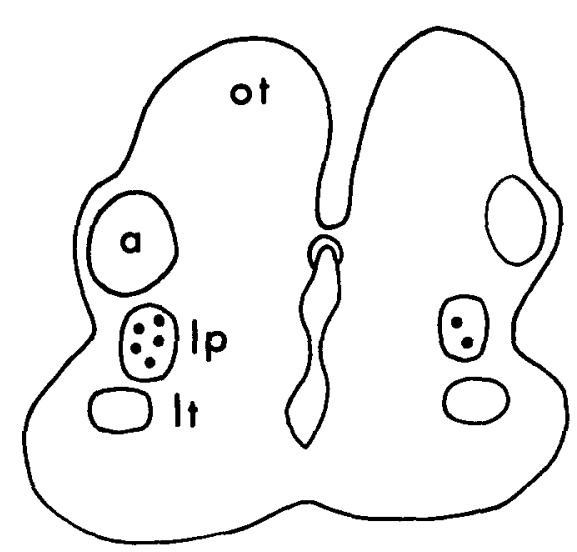

D

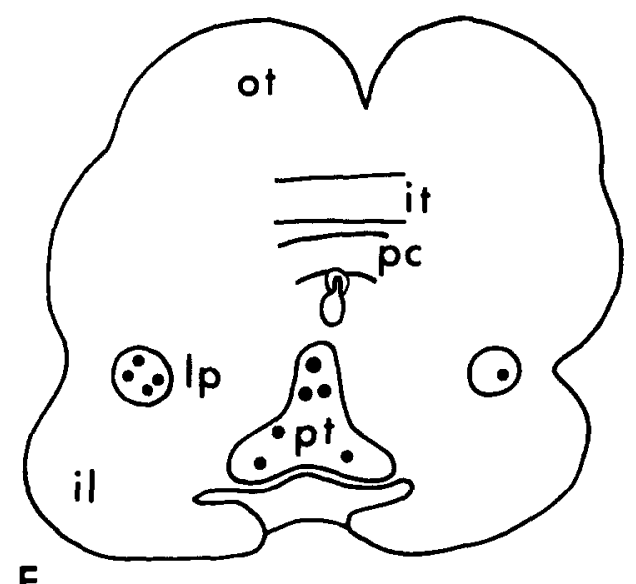

E

Fig. 3. Charting of the locations of retrogradely-filled cells in the diencephalon (B-E) following a large injection of HRP into the telencephalic pallial area responsive to visual and electrosensory stimuli (A). a, anterior nucleus of the lateral mesencephalic complex; at, anterior thalamic nucleus; hc, habenular commissure; il, inferior lobe of hypothalamus; it, intertectal commissure; lp, lateral posterior thalamic nucleus; lt, lateral tuberal nucleus; m, marginal optic tract; ot, optic tectum; pc, posterior commissure; pt, posterior tuberal nucleus.

with the head negative relative to the tail, were largest and had the shortest latencies $(45-60 \mathrm{~ms})$. The evoked potential responses consisted of a single negative potential which habituated at iterative rates of
$0.5 / \mathrm{s}$ and greater. Unit responses to fields as weak as $0.5 \mu \mathrm{V} / \mathrm{cm}$ were recorded from the lateral posterior nucleus (Fig. 4B).

No electrosensory responses were recorded in 
A

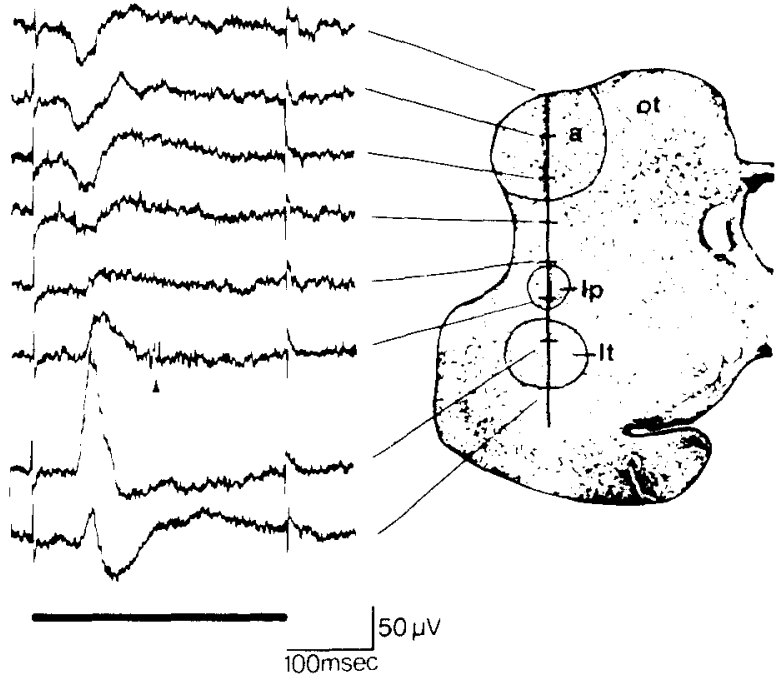

B

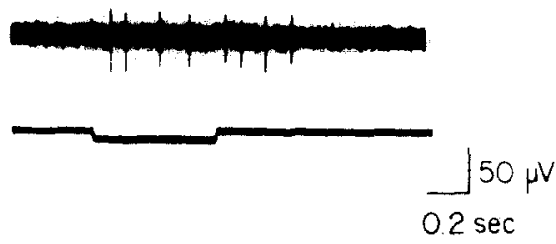

Fig. 4. A: averaged evoked potential responses in the diencephalon following stimulation with uniform electric fields in the water around the fish. Multiple unit responses are apparent despite signal averaging, superimposed (arrowhead) on the evoked potential wave recorded from the lateral posterior nucleus. The stimulus was an electric field of $50 \mu \mathrm{V} / \mathrm{cm}$ aligned parallel with the longitudinal axis of the fish with the head negative relative to the tail. The stimulus period is indicated by the bar below traces and brief artifacts are present at stimulus onset and offset. Each trace is the average of 4 trials. Note positive voltages are downward in this figure only. B: responses of a single unit recorded in the lateral posterior nucleus to uniform electric field stimuli. The field orientation and polarity is the same as in A. Top: actual voltage record of the unit's response to a field of $50 \mu \mathrm{V} / \mathrm{cm}$. Bottom: raster display of the unit's responses to fields of decreasing intensity. Five trials are shown for each intensity. a, anterior nucleus of the lateral mesencephalic complex; lp, lateral posterior thalamic nucleus; It, lateral tuberal nucleus; op, optic tectum.

many electrode tracks through more medial portions of the thalamus and posterior tuberal nucleus. We have also not yet localized electrosensory responses in the anterior thalamic nucleus.

Electrosensory evoked potential and unit responses recorded in electrode tracks through the lateral diencephalon were not limited to the lateral posterior nucleus, but were also recorded at levels both dorsal and ventral to this nucleus. The evoked potential responses in many tracks were, in fact, largest ventral to the lateral posterior nucleus in the lateral tuberal nucleus (Fig. 4A). Single and multiple unit responses to weak electric fields were also recorded in the lateral tuberal nucleus. This nucleus does not appear to project to the medial pallium.

Dorsal to the lateral posterior nucleus responses were recorded in the optic tectum which is known to receive electrosensory fibers ascending in the lateral line lemniscus 3.5 . Electrosensory responses could also be reliably recorded in the anterior nucleus of the lateral mesencephalic complex (Figs. 4A and 5). The source of electrosensory inputs to this anterior nucleus is not yet known.

Visual evoked potential or unit responses (utilizing light flashes or optic nerve shock) were not clearly associated with either the lateral posterior or lateral tuberal nuclei. It is possible that the anterior thalamic nucleus is the diencephalic nucleus relaying visual information to the pallial visual area in skates but we have not yet demonstrated this electrophysiologically.
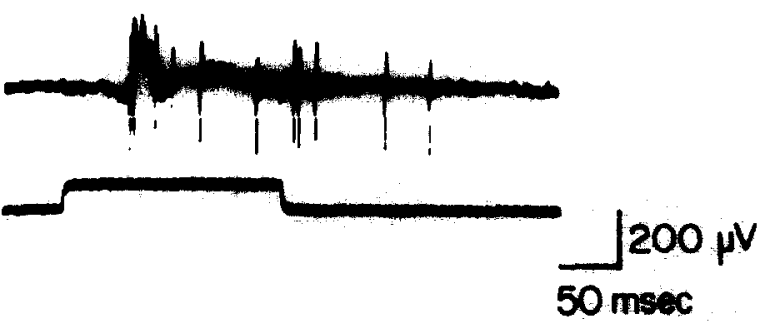

Fig. 5. Evoked potential and single unit activity recorded from the anterior nucleus of the lateral mesencephalic complex in response to uniform electric field (indicated in lower trace) in the water around the fish. The record shows 3 superimposed trials. The stimulus field was $50 \mu \mathrm{V} / \mathrm{cm}$ in intensity and was aligned with the longitudinal axis of the fish. Positive voltages are upwards. 


\section{DISCUSSION}

Averaged evoked potential and multiple unit recordings in Raja indicate that a portion of the telencephalic pallium is characterized by both visual and electrosensory inputs. These visual and electrosensory areas are found throughout much of the rostrocaudal extent of the pallium. Peak visual activity is $250-500 \mu \mathrm{m}$ superficial to the electrosensory activity; however, analysis of the recording depths, as marked by Fast green injections, suggests that both sensory areas are restricted to a single pallial cell group. We have found no cytological evidence for anatomical subdivisions of this cell group that could correspond to visual and electrosensory portions. Bullock and coworkers ${ }^{7,8.22}$ have previously recorded telencephalic evoked potentials to electrosensory stimuli in several elasmobranch species. Although their recording sites were not histologically identified, they reported that areas of electrosensory responses overlapped somewhat, but were not identical to areas of acoustic and visual evoked activity ${ }^{7.8}$.

At present, the homologue in other elasmobranchs of the sensory pallial area we have identified in skates is uncertain. In some sharks, the telencephalic hemispheres consist of thin walls surrounding an extensive ventricular system ${ }^{14,20}$. When this is the case, it is easy to recognize subpallial and pallial zones, as well as lateral, dorsal, and medial pallial areas. In many elasmobranchs a hypertrophy of the inner portion of the dorsal pallium occurs and is termed the central nucleus ${ }^{11,13,20}$. Both anatomical ${ }^{2,12}$ and physiological 2,6 studies indicate that the primary olfactory projections in elasmobranch fishes are restricted to lateral and ventral telencephalic areas not involving the central nucleus. Furthermore, Schroeder and Ebbes$\operatorname{son}^{3}$ and Luiten ${ }^{17}$ have demonstrated extensive projections to the central nucleus from several thalamic nuclei. At least one of these ascending thalamic pathways is clearly visual 9.17 .24 .28 and others may be electrosensory $7,8,22$ acoustic $^{8}$ and tactile 22 . The results of these studies suggest that the central nucleus of elasmobranch fishes may be a main target of ascending thalamic nuclei subserving several different sensory modalities.

In most skates and rays, however, the telencephalic ventricular system is reduced to a few isolated remnants, and the telencephalic walls are characterized by cell groups, whose boundaries are extremely indistinct. Thus, although the position and depth of our electrode tracks clearly indicate that we are recording from a pallial sensory area, this area could be interpreted as a very deep subdivision of the dorsal pallium (central nucleus) or as a subdivision of the medial pallium. The extreme depth of our recordings, as well as the position of the active pallial area adjacent to a remnant of the lateral ventricle and a portion of the medial forebrain bundle, strongly suggests that this pallial area is a subdivision of the medial pallium. Clearly, additional anatomical studies are needed to confirm this interpretation. In this context, our HRP experiments demonstrate that this sensory pallial area in skates receives contralateral input from an anterior thalamic nucleus that is known to receive both retinal and tectal inputs ${ }^{21,26,27}$. There occurs a similar visual projection to the medial pallium in anurans ${ }^{15,23}$.

Experimental determination of the efferents of this pallial sensory area in skates should establish its homology with pallial areas in other elasmobranchs, and this is critical. If we have correctly interpreted this pallial area in skates as medial pallium, this strongly suggests that sharks and skates possess pallial sensory areas that are not homologous, or that additional sensory areas remain to be identified in both groups of animals.

Our HRP and electrophysiological experiments indicate that the lateral posterior nucleus is the main source of electrosensory projections to the medial pallium. Schweitzer (personal communication) has recorded electroreceptive activity from this nucleus in the thornback ray. The evoked potential responses we recorded in the lateral posterior nucleus were similar although not identical in latency and waveform to the larger responses found in the lateral tuberal nucleus and might, therefore, be attributable to current spread. However, the multiple and single unit responses recorded in the lateral posterior nucleus establish that electrosensory activity is also intrinsic to this nucleus.

\section{ACKNOWLEDGEMENTS}

This work was supported by NIH grants to D.B. and R.G.N. The support of the Grass Foundation to D.B. during a portion of the study was also greatly appreciated. 


\section{REFERENCES}

1 Bodznick, D. and Northcutt, R. G., Segregation of electroand mechanoreceptive inputs to the elasmobranch medulla, Brain Research, 195 (1980) 313-321.

2 Bodznick, D. and Northcutt, R. G., Some connections of the lateral olfactory area of the horn shark, Soc. Neurosci. Abstr., 5 (1979) 139.

3 Bodznick, D. and Schmidt, A. W., Functional connections of the medullary electroreceptor nucleus of the skate, Soc. Neurosci. Abstr., B (II) (182) 763.

4 Boord, R. L. and Campbell, C. B. G., Structural and functional organization of the lateral line system of sharks, Amer. Zool., 17 (1977) 431-443.

5 Boord, R. L. and Northcutt, R. G., Ascending lateral line pathways to the midbrain of the clearnose skate, Raja eglanteria, J. comp. Neurol., 207 (1982) 274-282.

6 Bruckmoser, P. and Dieringer, N., Evoked potentials in the primary and secondary olfactory projection areas of the forebrain in Elasmobranchia, J. comp. Physiol., 87 (1973) $65-74$.

7 Bullock, T. H., Processing of ampullary input in the brain: comparison of sensitivity and evoked respones among elasmobranch and siluriform fishes, J. Physiol. (Paris), 75 (1979) 397-407.

8 Bullock, T. H. and Corwin, J. T., Acoustic evoked activity in the brain of sharks, J. comp. Physiol., 129 (1979) 223-234.

9 Cohen, D., Duff, T. and Ebbesson, S. O. E., Electrophysiological identification of a visual area in shark telencephalon, Science, 182 (1973) 492-494.

10 Daniel, J. F., The Elasmobranch Fishes, 3rd Edn., University of California Press, Berkeley, 1934.

11 Ebbesson, S. O. E., On the organization of the telencephaIon in elasmobranchs. In S. O. E. Ebbesson (Ed.), Comparative Neurology of the Telencephalon, Vol. 13, Plenum, New York, 1980, pp. 1-16.

12 Ebbesson, S. O. E. and Heimer, L., Projection of olfactory tract fibers in the nurse shark (Ginglymostoma cirratum), Brain Research, 17 (1970) 47-55.

13 Ebbesson, S. O. E. and Schroeder, D., Connections of the nurse shark's telencephalon, Science, 173 (1971) 254-256.

14 Johnston, J. B., The telencephalon of selachians, J. comp. Neurol., 21 (1911) 1-113.

15 Kicliter, E., Some telencephalic connections in the frog,
Rana pipiens, J. comp. Neurol, 185 (1979) 75-86.

16 Koester, D. M. and Boord, R. L., The central projections of the first order anterior lateral line neurons of the clearnose skate, Raja eglanteria, Amer. Zool., 18 (1978) 587.

17 Luiten, P. G. M., Two visual pathways to the telencephalon in the nurse shark (Ginglymostoma cirratum) II. Ascending thalamo-telencephalic connections, J. comp. Neurol., 196 (1981) 539-548

18 Mesulam, M. M., A tetramethyl benzidine method for the light microscopic tracing of neural connections with horseradish peroxidase (HRP) histochemistry. In Neuroanatomical Techniques, Society for Neuroscience. Bethesda, MD. 1979.

19 Murray, R. W., Electrical sensitivity of the ampullae of Lorenzini, Nature (Lond.), 187 (1960) 957.

20 Northcutt, R. G., Brain Organization in the cartilaginous fishes. In E. S. Hodgson and R. F. Matthewson (Eds.), Sensory Biology of Sharks, Skates and Rays, U.S. Government Printing Office, Washington, DC, 1978.

21 Northcutt, R. G. and Boord, R. L., Efferent projections of the optic tectum in the clearnose skate Raja eglanteria, Anat. Rec., 199 (1981) 185A

22 Platt, C. J., Bullock, T. H., Czéh, G., Kovacevíc, N., Konjevic, D. and Gojkovic, M. K., Comparison of electroreceptor, mechanoreceptor and optic evoked potentials in the brain of some rays and sharks, J. comp. Physiol., 95 (1974) 323-355.

23 Scalia, F. and Colman, D. R., Identification of telencephalic-afferent thalamic nuclei associated with the visual system of the frog, Soc. Neurosci. Abstr., 1 (1975) 46.

24 Schroeder, D. M. and Ebbesson, S. O. E., Non-olfactory telencephalic afferents in the nurse shark (Ginglymostoma cirratum), Brain Behav. Evol., 9 (1974) 121-155.

25 Schweitzer, J., Diencephalic responses to electroreceptive input in the thornback ray, Platyrhinoidis triseriata, Soc. Neurosci. Abstr., 8 (1982) 1026.

26 Smeets, W. J. A. J, Retinofugal pathways in two chondrichthyans, the shark Scyliorhinus canicula and the ray Raja clavata, J. comp. Neurol., 195 (1981) 1-11.

27 Smeets, W. J. A. J., Efferent tectal pathways in two chondrichthyans the shark Scyliorhinus canicula and the ray Raja clavata, J. comp. Neurol., 195 (1981) 13-23.

28 Veselkin, N. P. and Kovacevic, N., Nonolfactory afferent projections of the telencephalon of Elasmobranchii, J. Biochem. Physiol., 9 (1973) 512-518. 